\title{
The Impact of Technical Analysis on Stock Returns in an Emerging Capital Markets (ECM's) Country: Theoretical and Empirical Study
}

\author{
Mohamed Masry ${ }^{1}$ \\ ${ }^{1}$ Accounting and Finance Department, Faculty of Business Administration, Arab Academy for Science and \\ Technology (AAST), Alexandria, Egypt
}

Correspondence: Mohamed Masry, PhD, MA, MBA, BA in Finance, Accounting and Finance Department, Faculty of Business Administration, Arab Academy for Science and Technology (AAST), P.O Box 1029-Miami, Alexandria, Egypt. Tel: 203-556-5429/548-1163. E-mail: dr.m.masry@ gmail.com

Received: January 1, 2017

Accepted: January 30, 2017

Online Published: February 15, 2017

doi:10.5539/ijef.v9n3p91

URL: http://dx.doi.org/10.5539/ijef.v9n3p91

\begin{abstract}
Technical analysis, even if deliberated by some as purely conjecture, is still generally acknowledged as additional information to main brokerage companies. There are existent two reasons for the achievement of technical analysis and why its success is still debated: (1) stock return predictability stems from efficient markets that can be analysed by time-varying equilibrium returns, and (2) stock return predictability forms from prices wandering apart from their fundamental valuations. Fundamentally, both explanations show some kind of overall market inefficiency where investors are capable of exploiting. Therefore, technical analysis derived its importance from its ability to train investors to take investment decision based on historical trends of securities prices. To help find answers to the issues raised and to structure the study, the following general research question is set: is it possible for technical analysis to achieve abnormal returns in an Emerging Capital Markets (ECM's) country, more specifically, the Egyptian Stock Exchange? If yes, hence it could be possibly used to help individual investors to take effective investment decision. By means of theoretical and empirical investigation, this study provides significant evidences that technical analysis achieved abnormal returns in inefficiency periods. This study suggests that simple trading rules, more specifically; the simple moving average beat the standard buy-and-hold strategy for the Egyptian stock exchange.
\end{abstract}

Keywords: technical analysis, Efficient Market Hypothesis (EMH), Emerging Capital Markets (ECM's), behavioural theories, simple moving average rules, Egyptian stock exchange

\section{Introduction}

Technical analysis is a wide term that includes the usage of a range of trading strategies in international stock markets. The strategy that technical analysts use stems its power from the notion that upcoming stock prices are anticipated by means of the study of historical stock prices. However, this philosophy violates the random walk hypothesis that stock prices change independently of their historical trends and actions.

The efficient market hypothesis (EMH) indicates that investors cannot generate abnormal returns via depending on information enclosed in historical prices if the market is at least weak form efficient. The efficient market hypothesis recognises the notion that bases of expectable trends that offer significant abnormal returns are instantly shattered by investors. Through shattering these trends in the market, investors rapidly reduce any predictableness in the stock market. Investors who accept EMH try to form portfolios that optimally diversify risk or mimic the market. In contrast, technical trading investors try to regularly beat the market via revealing inefficiencies in market structure.

Numerous studies have dedicated on the usage of technical analysis in stock markets. But, research analysing the usage of technical analysis in emerging markets is inadequate. Thus, this study focuses on the profitability of technical analysis strategies in on one market of the emerging markets, i.e. the Egyptian stock market. The profitability of these strategies applied in emerging markets will be compared to the profitability of comparable strategies from previous studies of worldwide undeveloped and developed markets. Information and data whether historical, private or current, play a big role in taking investment decision, as it supports investors to the take right decision that help them to achieve their goals, and suits their personal circumstances. 
Investment decision is the most important factor in the investment process, which may results in whether achieving higher return or losses. Technical Analysis strategies are considered as the main tool for individual investors to take investment decision. Besides, it should be mentioned that this is the first study conducted in Egypt on technical analysis during periods of high volatility in the environment due to adverse economic and political conditions after the $25^{\text {th }}$ of January's revolution. Therefore, this study compares between the profitability of technical analysis before and after $25^{\text {th }}$ January revolution, considering the inefficiency of the Egyptian stock market in the second period than first period due to high political instability, apart from macroeconomic problems that are common to other countries within the emerging markets. Thus, it is important to realise how technical analysis practices affects stock returns in such markets.

The main aim of the study is examining the profitability of Moving Average ability in Egyptian securities market, because moving average rules is the simplest rule of technical analysis, which is easy to be learned and applied by individual investor. Moreover, to detect abnormal returns of the following technical analysis trading strategies, this study as well analyse the success of a "buy-and-hold" strategy in the same period. These strategies are assessed merely on their ability to deliver optimum exit and entry points and to expect future stock prices. The presence of Egyptian stock markets data will offer an opportunity to indicate remaining profitability and abnormal return from market that is not considered "developed" or "efficient." This market may not be considered as liquid or deep as other international markets. Characteristics of the Egyptian market that this study is primarily interested in examining are the volatility and high risks, the relatively low volume, and the regulatory constraints, which all contribute to probable profitable situations for technical trading strategies.

However, it should be mentioned that large proportions of the investors in the Egyptian stock market are individuals rather than professional financial institutions. The individual transaction accounts for $56 \%$ of the total volume of Egyptian stock trading. These investors suffer from the lack of qualification and experience in designing their investment strategies and effective market timing. Such deficiency makes the decision-making process based on speculative performance rather than a scientific investment base. This is because the individual investor cannot handle the same types and tools of technical and fundamental analysis, performed by professional financial institutions that are characterised by appropriate methods of specialised analysis and evaluation (Masry, 2016a).

This study is organised into six sections. Section 1 presents the introduction and motivation of the study. In this section, the researcher motivates his arguments for choosing the research topic. The matters dealt with include the need for research in ECM country aimed at the current practices and the changes taking place in developing stock markets. Section 2 includes the theoretical background, the arguments for technical analysis, the process of technical analysis and its strategy for expecting stock return. The aim of this section is to build up the theoretical framework of the study, which serves as the basis for the data collection and analysis. Section 3 presents the lessons to be learned from previous technical analysis studies and the limitations of technical analysis theories in relation to ECM countries. Section 4 deals with the research methodology, and provides a description of the data collection and analysis methods used. Finally, section 5 presents the analysis of the study and section 6 concludes the study by presenting the conclusions and implications of the study.

\section{Theoretical Framework}

Technical Analysis (TA) take account of creating investment decisions based on historical trading data. It aims to launch selling and buying rules that maximise return and still control risks of loss. Conversely, as stated by the $\mathrm{EMH}$, this endeavour is eventually unworkable. The EMH indicates that all relevant and available information are already integrated with security prices. As technical analysis uses only past and current trading data, it is impossible to attain abnormal positive returns by applying these technical trading procedures. If investors could create money from applying these trading procedures, this would designate that the market is inefficient. Hence, the question of whether technical trading rules can reliably create returns becomes an empirical and theoretical issue concerning efficiency of stock markets.

Despite the fact of considerable amount of studies on the predictability of asset return have thus far been conducted, the numbers of such studies that have inspected technical analysis as a means of method of testing market efficiency and expecting future price of return movements is rather small. There are only a small amount of predictability of assets returns studies and tests of the weak form efficiency that can be categorised under technical analysis. The literature appraises an increase in the level of the debate on the effectiveness of technical analysis. Additionally, each side seems to have hardened its resolution, with evidence and arguments defending the null of market efficiency from one side, and the other side proposing presence of significant abnormal returns from depending on past information. 
In addition, many studies have focused on the usage of technical trading strategies in stock markets. But, research analysing the usage of technical analysis in ECM is inadequate. A theoretical framework that includes the wider context of ECM countries is therefore indispensable. In designing the research framework, the following criteria were considered: the model has to meet the main aim of the study as described in section 1 and it has to be suitable for application in the Egyptian stock market environment and its socio-economic and political contexts.

\subsection{Definition of Technical Analysis}

Before discussing the theoretical framework of technical analysis, it is necessary to define what technical analysis is. Edward and Magee (2001) define technical analysis as the knowledge of recording, typically in graphic form, the actual history of trading (volume of transactions, price changes) in a definite stock or in "the Averages" and then realising from that pictured history the possible future trend. Furthermore, Murphy (1999) describes it as the learning of market action, mainly using charts, for the sake of predicting upcoming price trends. Market action refers to three sources of information, accessible to the technician, i.e., open interest, volume and price. This action is the consequence of the mass behaviour of buyers and sellers or rather, crowd behaviour. While Kirkpatrik and Dahlquist (2016) define technical analysis as the study of historical market data, mainly volume data and price, this information is used to make investing decisions or trading. Besides, Achelis (2001) defines technical analysis as the method of analysing a security's historical prices in an effort to expect possible future prices.

From previous definitions, one can conclude that technical analysis focuses on the market actions rather than the goods in which the market deals. It depends mainly on graphs and charts in using market data to forecast future price trend. Technical Analysis patterns grade from simple approaches to more complex, it is a term including numerous strategies forecasting patterns and directions of stock prices (Peterson, 2006). This approach focuses on monitoring and tracing price movements in the past to deduct its pattern in a way that enables forecasting future stock price, helping in taking a good investment decisions (Hendy, 2013).

Users of TA are Chartists, as they mainly depend on charts, they think that history trends to repeat themselves, thus they can use these patterns in predicting stock prices (Gencay, 1998). Although there is no reason explaining why patterns are repeated, TA approach determines time of direction changing (Upwards or Downwards), which helps the investor to choose suitable time to enter or exit from the market. Others see that TA Is a reflection of the notion that prices are moving in the direction according to the change in investors' attitudes towards the political, economic and monetary situations. Evident skill technical analyst is to identify trend changes at an early stage and to use this knowledge in the formulation of appropriate strategies until the appearance of evidence that proves the trend is fluctuating (Park, 2007).

In summary, TA value comes from the fact that current market statics are not enough to transmit information, comparing previous prices to current ones is not enough to enable investors to have more assessments that are accurate. On the other hand, market volume provides decision makers with information about quality of traders details, which cannot be defined through prices, as both market volume and prices provide together more valuable information than just observing prices, whereas main information which affect the price - economic, political, psychological - come from volume of transactions and prices of securities.

From the above, it can be concluded that most of abovementioned definitions contain two or more of the three following points:

- Prices move in trends.

- History repeats itself.

- Market action discounts everything.

In short, TA analyses history of past trends to evaluate investments nowadays, this philosophy is based on above-mentioned three points that allow studying charts and current data so one can expect future market directions.

\subsection{Efficient Market Hypothesis (EMH)}

Efficient Market Theory indicates that stock prices represent the whole thing that is known about the stock at a particular moment. This theory concludes the belief that it is impossible to estimate prices, subsequently stock prices already reflect everything that is presently known about the stock.

The EMH has dominated practical finance literature, mainly as a consequence of the study of Fama (1970). A massive wealth of accompanying literature during the 1970s provided provision for the weak form of this 
hypothesis, in which it is proposed that changes in historical stock prices cannot be used to estimate future stock returns. Alongside the same disposition, market efficiency suggests that stock prices respond accurately and to quickly related information. If prices are mean deteriorating, then it follows that the price level will come back to its trend path over time and that it might be probable to estimate future movements in prices based on historical behaviour. On the other hand, if prices follow a random walk process, then any revelation to prices is permanent. This indicates that upcoming returns cannot be expected based on historical movements in precious prices and that markets volatility increases deprived of bound (Cheung et al., 2004).

The EMH indicates a perfect capital market in which all information is freely obtainable to all participants; all participants are price takers; and there are no transaction costs. Based on these assumptions, companies make effective investment decisions, and consumers select securities. Under this supposition, the EMH can be tested by measuring the changes of stock prices and revealing information to all participants. Experiential studies in efficient markets identify three levels of market efficiency, which are founded on the amount of information that is shown to the market, 'the set of information'.

Theoretically, there are three information sets of the EMH. In weak-form efficiency, the set of information is based only the past trends of returns or prices; in semi-strong form efficiency, the set of information includes all public information and in the strong form, the information set ranges to the private information. Assumed an information set, studies of market efficiency test and predictability whether trading founded on the identified information set produces abnormal returns or not. The abnormal returns are the variances between the expected returns and the realised returns with the specified information set. The main null hypothesis in most experiential researches is that, founded on information at time $t$, it is not probable to earn anticipated returns or profits exceeding equilibrium anticipated returns or profits at time $t+$.

The supposition that investors are rational and that their behaviour is identical supports the asset pricing classical theory. The study literature review notifies that these suppositions are theoretically accountable for the inventive view of the EMH, that stock prices are unpredictable.

Consistent with this theory, the core philosophy of non-dependency in stock return series lies in the belief of restated anticipations of rational investors. It is claimed that any effort to estimate a positive upcoming return generates otherwise to positive current return as investors attempt to take the action before any price move (Samuelson, 1965). More commonly, this infers that the information that might be used to expect stock return is previously mirrored in stock prices. Once there is any information demonstrating that a stock is under-stated and consequently provides return opportunity, investors drove to purchase the stock and hence rise up its price to a rational level, wherever only regular return can be estimated (Luca \& Brorsen, 1989). This argument entails investors to be rational and not to have diverse comparative advantages in the gaining of information.

In conclusion, if prices are bid instantly to rational levels, assumed all accessible information, it might be that they decrease or increase simply in reaction to new information. Consequently, new information should be erratic; even though where this is probable, at that moment expectation would be part of today's information. Hence, stock prices that change in reaction to erratic information likewise might change randomly. This is the core of the belief that stock prices must follow a random walk, more specifically; prices change must be unpredictable and random.

\subsection{Behavioural Theories}

Lately, studies on technical analysis have attempted to encompass investigations of behavioural finance in order to disrupt EMH further. West (1988) observed theories that there be disparate variances in stock prices volatility as compared to volatility of expected or fundamentals returns. West advises that it might be essential to deliberate non-standard models directing on psychological or sociological mechanisms for instance momentum in stock prices. Following rising indication of systematic patterns in stock returns series, new paradigms capable of depicting a wider picture of the prices behaviour in speculative markets and grounded on the supposition of psychological biases in the way investors react to new information have been offered. These offered paradigms encompass behavioural aspects of investors and are commonly referred as behavioural theories. For instance, overreaction, overconfidence and optimism concepts behind herding models mentality, asymmetric information diffusion process and ECM assumptions are noticeable in several methods employed by technical analysts containing moving averages based trading system.

\subsubsection{Overreaction}

Overreaction is concerned by the amount of investor's reaction resulting from the appearance of information. Day and Wang (2002) claim that if stock prices steadily increased, at that moment their reverse would be 
expectable from historical return data only. Day and Wang (2002) propose two explicit assumptions in this regard: 1) consequent movements in the opposed direction will follow extreme changes in stock prices. 2) The greater extreme initial price change, the superior will be the consequent alteration. Consistent with the long-horizon reversal and overreaction assumptions, investors are likely to react excessively to new information and, hence, previous failures will generate greater return than the previous winners.. Day and Wang's (2002) discoveries support the contrarian strategy and fitting well with the long horizon reversal effect. They define this effect with the overreaction hypothesis. In short overreaction can be defined as a market assumption that investors and traders respond disproportionately to new information about a particular security. This will result in a dramatic change in the price of the security, so the price will not fully reflect the actual value of the value immediately after the event. As a general rule, the fluctuation in the price of excessive reaction is not sustainable, as the stock price will tend to return to its real value over time.

\subsubsection{Overconfidence and Optimism}

Overconfidence occurs when investors believe that their knowledge is more accurate than it actually is. It suggests that investors feel a too high probability for an event when they believe will happen. Daniel et al. (1998) argue that investors are too confident, leading investors to overestimate their ability to control events, underestimate risks and overestimate their knowledge (Gehrig \& Menkhoff, 2006). One reason may be that they have had outcomes to the "uncontrollable" environment and have good results to their own abilities. This can cause an illusion of control over the environment.

Self-attribution leads investors to be too confident instead of focusing on an accurate self-assessment. In other words, self-attribution leads investors to underweight the public in relation to private information. The theory of self-deception suggests that a tendency to change attitudes to correspond to historical actions is a mechanism designed to influence investors as they are skilled decision-makers.

Daniel et al. (1998) provide a theory where investor confidence grows when public information is consistent with their identifiable information, but does not fall when public information opposes this information. Price movements resulting from identifiable information are on average partially reversed. This indicates that price movements resulting from the arrival of public information are positively associated with future stock price fluctuations.

\subsubsection{Herding Models}

When financial markets behave anxiously, the financial explanation often attributes this behaviour to instinct "herd" investors. By favouring rational explanations, economists have taken up the notion again and tried to describe situations in which investors rationally "herd", although initially outside the financial sphere (in fields such as fashion or technological choice).This type of information gathering takes place in situations where people observe the actions of others, draw information from them and then, apparently, ignore their own information, follow the majority action. The movements of visible traders encourage others to follow, causing discontinuous price jumps in one direction or the other with prices deviating far from the fundamental value of the asset.

Herding models are emerging within the framework of behavioural finance theory, which attempts to clarify stock prices behaviour. Studies of herd behaviour or "following the trend" generally indicate that the phenomenon could be responsible for events such as the 1987 stock market crash (Shiller, 1990). Froot et al (1992) reported that the herding behaviour of traders can lead to inefficiency of information. In the technical analysis framework, Froot et al (1992) argue that the fact that many traders use chartist models can be enough to make a positive return for traders who already know how to trace.

\subsubsection{Asymmetrical Information Diffusion Process}

According to the model of Hong and Stein (1999), investors are classified as uninformed and informed. Uninformed investors are those responsible for the momentum effect and trade observed on the basis of recent price information. While the investor informed trade only on the basis of new information on cash flow. As information is received, the information gap between the two groups narrows. This translates into the long-term effect of average reversion. The theory suggests that the information dissemination process should be slower for small firms, where corporate data are not exposed to the depth of analysis that is given to large firms.

\subsubsection{Emerging Capital Market (ECM)}

Emerging capital markets interest numerous investors mainly during times of financial instability in developed markets. Moreover, investors seeking to diversify their portfolios often discover ECM attractive. Since many countries, including Egypt, currently considered as ECM have undergone immense financial liberalisation 
processes. On November 2016, the Egyptian state implemented new structural adjustment policy (SAP) which has resulted in extensive social and economic changes. The program introduced numerous reforms including: huge exchange rate floatation, interest rate liberalisation, financial sector reform, reduction in subsidies and foreign trade liberalisations. In relation to the Egyptian move towards a market-based economy; the main goal of the reform program was to: create an open, market-orientated, decentralised economy receptive to private sector participation and foreign direct investment.

\section{Content and Definition}

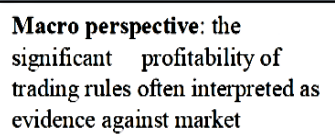

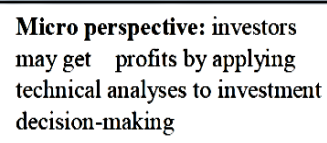

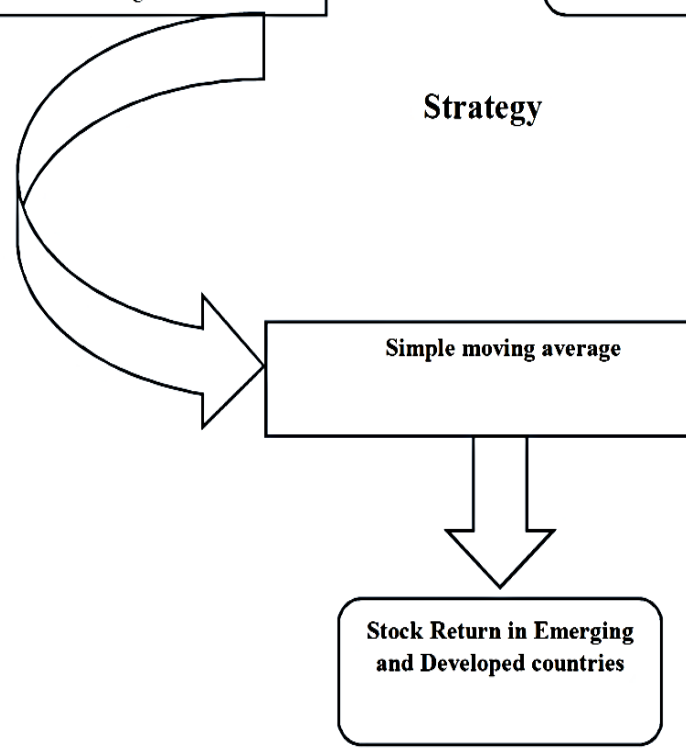

Process
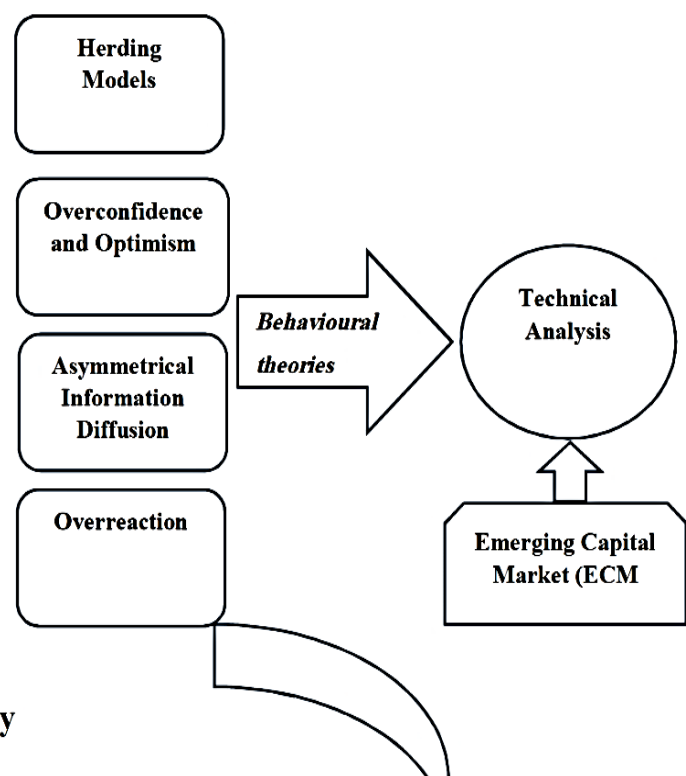

Figure 1. The theoretical framework of the study

Characteristics, such as low correlations with developed markets and higher average sample yields, resulted in a substantial increase in capital flows (Bekaert \& Harvey, 1997). Despite this intense increase in capital flows, little research has examined the cost-effectiveness of technical analysis in these markets. Bekaert and Harvey Characteristics, such as low correlations with developed markets and higher average sample yields, resulted in a substantial increase in capital flows (Bekaert \& Harvey, 1997). Despite this intense increase in capital flows, little research has examined the cost-effectiveness of technical analysis in these markets. Bekaert and Harvey (1997) suggest that ECM exposure shows both greater stock return persistence and higher volatility than developed markets. This evidence pokes holes in efficient market theory and reveals the probability of at least some market inefficiency that could offer chances of abnormal return for investors. ECMs may reveal these characteristics, as their low liquidity, overall slimming and non-synchronous trade patterns provide significant evidence of the potential for market inefficiency. Other research such as (Dewachter \& Lyrio, 2005); suggest that 
investors in ECM respond more slowly and more gradually to information in relation to developed markets. This "learning effect" is important in the analysis of other non-linear, non-normal and long-term dependence effects of ECM.

In short, in this section, the theoretical framework that formed the basis upon which the study data was collected and analysed is presented. Figure1 summarises the discussion regarding the theoretical framework of the study.

\section{Previous Studies}

As pointed out by Bagheri, Peyhani, and Akbari (2014), professional investors use two main types of analysis to make precise decisions on financial markets: fundamental and technical. Fundamental analysis uses global industrial, trade and economic indicators. Technical analysis creates its decisions based on historical prices, assuming that historical behaviours have an effect on the future evolution of stock market returns. In technical analysis it is common to use indicators (Patel, Shah, Thakkar, \& Kotecha, 2015, Liu, 2015; Zbikowski, 2015), that are generated by applying more or less compound formulas to historical returns. Subsequently, investors explore market behavior using technical analysis to anticipate future market trends. From a micro perspective, investors could benefit by applying technical analysis to investment decision-making. From the macro perspective, the significant profitability of the trading rules regularly deduced as evidence against the market efficiency. Discussions on the effectiveness of technical analysis have covered wide areas of research in recent years. Most initial studies support the random walk hypothesis, which means that technical analysis is worthless. Consequently, a number of previous studies in both emerging and developed markets conducted and presented separately in the following sub-sections in order to reach the unreliability or credibility of the technical analysis method to expect the stock value returns.

\subsection{Studies Conducted in the Emerging Markets}

In a study of emerging markets conducted by Bessembinder and Chan (1995) to investigate the feasibility of trading rules for technical analysis in Asian stock markets, where they assessed whether changes in many Asian equity indices can be anticipated via some simple forms of technical analysis or not. They have determined that some of the technical trade rules have undue importance in the ability to expect changes in stock prices; so if the Asian stock market is inefficient, technical analysis might be able to exploit the lack of that efficiency. The results explained that these rules could be relatively effective in emerging markets in Thailand, Malaysia and Taiwan; however, these rules have had an illustrative or explanatory influence on certain developed markets, such as Japan and Hong Kong. In conclusion, they stated that the inefficient stock market is considered a high predictive market.

Ratner and Leal (1999) examined the possible return of ten "long-term moving average (VMA)" trading rules in ten of the emerging markets in Asia and Latin America. The results indicate that Mexico, Thailand and Taiwan are markets where technical trading strategies could be profitable, but they have not found solid evidence of returns in other markets. However, they found that $82 \%$ of the bargaining rules verified in groups expect real changes in the series of returns. In addition, Gunasekarage and Power (2001) intend to implement a technical analysis of the performance of a set of technical trading rules "simple moving average" in four of the emerging stock markets in Asia. Moreover, they studied the effects of efficient market hypothesis results in the weak form. They have established that the possibility of obtaining returns by studying the moving average values, which are equal to those obtained through hold and buy strategy, increasing the value of excess returns for investors on different equity markets in Asia.

In addition, Tian, Wan, and Guo (2002) sought to examine the returns to technical trade rules and the efficiency of financial markets, as well as emerging markets (Chinese stock markets) and developed markets (US stock markets). In order to examine which markets have the technical trading rules better in expecting changes in stock prices under different levels of efficiency. They concluded that for the US market prior to 1975 there was the possibility of applying technical analysis rules and the ability to predict changes in stock prices and yields. While from 1975 to 1991, these rules are insignificant as a result of increasing the efficiency of the US market. Therefore, this study supports technical strategies in its ability to expect changes in earnings and excess returns from stocks during the study period on the Chinese stock market.

Furthermore, Atmeh and Dobbs (2006) focused on analysing a performance of the moving average rules in the Amman Stock Exchange and used the time series of the Jordan Daily Market Index over the period 1992 to 2001. They clarified that technical analysis could anticipate for changes in stock prices. While Kung and Wong (2009) tested the profitability of technical analysis, in the Singapore stock market before and after the Asian financial crisis. They are interested in whether these techniques have led to lower profitability for investors who use technical rules or not. The results indicate that the three trading rules: bargaining range, double moving average 
and single moving average constantly produce the highest annual returns before the Asian financial crisis compared to the period 1999-2007 after the period of reform. They confirmed that the efficiency of the stock market in Singapore has increased considerably due to the techniques applied after the Asian financial crisis.

Recently, by means of more advanced techniques of technical analysis, Vasileiou (2014) recognised that behavioural finance theories might provide some alternative and useful justifications concerning some of the reasons that contribute to the Greek stock market's inefficient environment. De Oliveira, Nobre, and Zárate (2013) used financial and economic theory, combining time series analysis, fundamental analysis and technical analysis, to expect price behaviour in the Brazilian stock market by an Artificial Neural Network (ANN). Besides, Patel et al. (2015) compared four prediction models to forecast the trend direction in the Indian financial markets: random forest, Support Vector Machine (SVM), Artificial Neural Network (ANN), and Naive-Bayes. The results recommended that random forest beats the three other expectation models on overall performance. While, Hu et al. (2015) offered a hybrid short-term and long-term evolutionary trend-following algorithm that combines extended classifier systems (XCS) with trend-following investment strategies. Throughout this approach, they present a trading rule, which chooses stocks by different indicators in Shanghai stock market.

Finally, Wafi, Hassan, and Mabrouk (2015) sought to compare the credibility of fundamental analysis and technical analysis in forecasting the value of the Egyptian stock market by applying to 37 non-financial firms between 1998 and 2009. By means of time series and cross-sectional analysis, they concluded that the technical analysis approach yielded better results than fundamental analysis approach.

In short, it is clear from the first discussion that technical analysis rules are effective and are capable of predicting stock returns, which is due to the lack of financial efficiency of these markets, making it possible to apply the simple techniques of profitable trading rules.

\subsection{Studies Conducted in the Developed Markets}

Brock et al. (1992) proposed two bases for the technical analysis strategy: moving average and also levels of support and resistance to trade, by application in the Dow Jones index, where they used time series data during the Period from 1897 to 1986. By supporting these technical analysis strategies and receiving returns from sales and purchasing indicators, one can rely on them to expect returns that deviate from normal returns. Similarly, Kwon and Kish (2002) conducted an extension study of Brock et al. (1992), using the NASDAQ and NYSE indices.

After applying the technical analysis rules used by Brock et al. (1992), the results showed the ability of the models to be expected in the first and second periods, these results generally appear to be identical to the complete sample (1962-1996), confirming the models' expectations effectiveness. However, the expectation for the third period (i.e., 1986-1996) has disappeared for the NYSE. For the NADAQ index, the last sub period (i.e. 1985-1996) refers to the general weakness of the technical rules of negotiation compared to the whole period (1973-1996). Therefore, this indicates that the market has become more efficient in recent years. Hence, this improvement could be explained by improvements in information technology and perhaps clarifies the fact that technical trading rules are much more important in small stocks than in large stocks.

More recently, Mallick, Lee, and Ong (2008) applied genetic programming as a trading rule on the stock market, compared to the moving average trading rules for about 30 stocks quoted in the Dow Jones Industrial Average (DJIA), over the period from January 2000 to December 2005. The results show that the trading rules for genetic programming have resulted in better yields for the buy and hold strategy than the signals resulting from moving average trading rule. Moreover, Malliaris and Malliaris (2013) examined the movements of the S\&P 500 index using several methodologies such as time series techniques, econometric modeling, and theories of technical analysis of behavioural financing. They stated that specific conditional predictions defeat the unconditional random walking model.

While Gottschlich and Hinz (2014) suggested a Decision Support System (DSS) that allows investors to take account of the crowd's recommendations in their investment decisions and used it to manage a portfolio in Frankfort stock Exchange. However, Silva, Neves, and Horta (2015) apply a Multi-Objective Evolutionary Algorithms (MOEA) with two intentions, risk and return, to enhance portfolio management. They determined that in order to obtain stocks with high valuation potential, it is necessary to select firms with low price earnings ratio, a lower market capitalisation, and high operating leverage as well as high rates of revenue growth in the S\&P 500 for the period June 2010 until 2014.

While Gottschlich and Hinz (2014) proposed a Decision Support System (DSS) that allows investors to consider the recommendations of the crowd in their investment decisions and use them to manage a portfolio in Frankfurt 
stock market. Finally, Silva, Neves, and Horta (2015) apply a Multi-Objective Evolutionary Algorithm (MOEA) with two intentions, risk and return, to improve portfolio management. They have determined that in order to obtain securities with high valuation potential, it is necessary to select firms with a low price-to-earnings ratio, a lower market capitalisation and high operating leverage, and high growth rates of the S\&P 500 for the period from June 2010 to 2014.

Through the analysis of theoretical framework generated by the study supported by previous studies applied, in both emerging and developed Markets, the researcher observes the following:

First: In emerging markets, rules of technical analysis are effective and have a high capacity to expect a return of shares. This is due to the lack of financial efficiency of these markets, making the use of simple technical trading rules cost-effective and feasible.

Second, in developed markets, it may be noted that the technical trading rules in previous studies in developed markets have achieved returns as before the 1980s, but after improvements in the transparency of information and technological developments, as well as the large size of the market, Technical trading rules have become an impractical strategy. On the optimistic side, there are studies that support the power of technical analysis in developed markets, using advanced application and models with the same technical analysis, e.g. genetic programming, genetic algorithm, Analysis of neural networks, if not merge more than one model to extract a recommended model that leads to increased precision in expectations.

Third: A technical trading strategy consists of a set of trading rules used to create trading indicators. In this study, the simple moving average strategy is chosen as an indicator of technical analysis. Trading systems based on the simple moving average are the most popular and simplest trend tracking systems for practitioners. Moving averages show effective performance in markets characterised by indirect price action. More precisely, moving averages have good results in scenarios where strong trends are developing. When the market is "congested" moving averages would tend to give investors something known as "whipsawing". Whipsawing occurs when buying and selling signals are created, but by the time the investor enters the market, the trend has devalued and significant returns are no longer feasible. A solution to whipsawing is the development of a band surrounding (filters) moving averages that tries to eradicate less profitable trend signals. Thus, this justifies the need for filters rules to be combined with the simple moving average in this study.

In brief, throughout the literature review generated by the study, it is clear that the theoretical framework of the study has not only limited importance and usefulness in emerging markets, but also expanded to achieve the ability to forecast in developed markets. However, the main differences are how to apply using advanced models as previously explained. Hence, returns based on moving averages are compared with returns gained from buy and Hold Strategy based on the above theoretical evidences and literature following hypothesis is developed:

H1: There is significant relationship between returns based on moving average rule applied by technical analysis and the Buy and Hold Strategy.

H2: There is significant relationship between returns based on moving average rule applied by technical analysis and the Buy and Hold Strategy before and after $25^{\text {th }}$ of January revolution.

However, it is worth mentioning that researchers face a number of complicated positions and meanings regarding their research activity. Consequently, research design is affected by questions regarding the nature of knowledge and the nature of reality. The answer to the question of knowledge affects the implication of the way that methodology is acquired. Methodology, then, is a way of gaining knowledge about the world; trying to discover the task of finding out what is believed to be true. Departing from such discussion, the research methodology and design are discussed in the next section.

\section{Methodology}

There are diverse layers that tie the elementary assumptions prepared to the methodological techniques engaged. These layers range from the ontological and epistemological layers to the methodological techniques employed to inspect the research theoretical perspectives. This study is depending wholly on the quantitative approach, which is commonly located in the positivist social sciences paradigm, which principally reflects the scientific method of social sciences (Jennings, 2001; Masry, 2015b). The positivist paradigm adopts a deductive approach to the research process. It hence starts with theories and hypotheses on a specific phenomenon, gathers data from the real-world site and consequently analyses the data statistically to support or reject the initial hypotheses (Masry, 2016b; Welman \& Kruger, 2001). The aim is to investigate or validate a proposed theory, instead of constructing one. Therefore, it can be seen that this study proposes a theoretical framework for the whole study, also serving as an organising model for the research hypotheses and for the whole data collection process. 
Concerning the previous studies methodologies the researcher noticed that there are extensive criticisms can be found in the quantitative studies applied in assessing technical analysis and stocks return. Firstly, the extent to which these results can be generalised across the developing countries is not clear, given that most of the studies focusing on developing countries were mixed with data from developed countries. Secondly, Most of the past studies tended to be at the high level of international comparison, and hence suffered from possible data heterogeneity problems. Furthermore, most of these studies were reliant on creating a data set from a mixture of sources, with consequent potential data inconsistencies due to different accounting practices used by different countries.

\subsection{The Sample and the Period of the Study}

The whole research procedure is objectively constructed, and the results are regularly representative of the population being studied. The population of the study is represented in shares of companies that traded within the Egyptian stock Exchange, choosing largest number of active traded shares EGX70 previously known as CASE70. Shares which do not include any data till 22/06/2015 was eliminated, to provide information about closing price of all shares in different dates from 01/01/1995 till 22/06/2015, and to obtain data about Egyptian stock exchange after 25th January 2011 revolution, total number of shares reached 47 share, deleting data of many shares in order to unify period of the study from 24/01/2008 till 22/06/2015, and after preparing moving average for 5 days, 50 days, and 150 days. It was essential for the researcher to delete 150 views of trading days from 24/01/2009 till 01/08/2009 due to issues related to calculating the moving average.

In addition, the researcher deleted a share because its views were less than the views of 46 shares, which indicates missing views during this period. Therefore, the sample of the study is composed of 46 shares of EGX70 indicator for 7 years, 4 months, 20 days during period from 02/08/2008 until 22/06/2015, to include 76506 views for each share. Strategy of Buy and Hold is represented by average of daily return of 46 shares during the study.

\subsection{Strategy and the Rules Used by Technical Analysis in the Study}

Variable length moving average strategy of trade is used in this study, which depends on buying the share when a buy sign is produced by Technical Analysis rule, so period between buy and sale is variable as per difference of days between the two signals (Peterson, 2006). However, six Technical analysis rules are used to generate buying and sale signals for the share`s sample, which formed according to: Simple Variable moving average and Simple Variable moving average improved with price filter.

\subsubsection{Simple Moving Average Rules}

Trading rules models are used to assess whether performance models can be profitable. This method is based on the hypothesis that the technical trading rules benefit from a positive series correlation in the return series where the autocorrelation bias in the time series should continue in the same direction. Assuming the massive amount of trade rules attainable, it has always been hard to select the type and number of trade rules to be carried out in a study of this type. The selection of trading rules is an inquiry interrelated to the erroneous results and the snooping of the data. To avoid these problems, the researcher assumes: 1) the trade rules most used in the industry and 2) those that are simple to implement. A buy signal is given when the short moving average exceeds the long moving average. The 1 and 0 are the percentage band filters, while 0 for the non-filter and 1 devoted for the $1 \%$ filter. The $\%$-band filter is used to reduce the number of false signals. The band filter is presented around the slow average. If the price of the fast moving average crosses the slow average with a volume larger than the band, a signal is produced; if not the position on the market is preserved. The two long (L) and short (S) moving averages (MA) are calculated at time. It is the price average during limited period of time, e.g.: moving average during five days, every day of trade as average of five days of closing prices are collected, then total is divided by 5 . Latest five days account are calculated by adding price of new day and deleting oldest price, Technical analyst believes that last price is most important information of share.

Moving average of short term and of long term is compared to produce signals of buying, it is a buy signal when moving average of short term is more than moving average of short term, and sign of sale when variable average of short term is less than variable average of long term, Two moving average of short term are used, one day and five days, Two moving average of long term are used, 50 days and 150 days, Three rules of trading are formed which is: $(1,50,0),(1,150,0),(5,150,0)$, First rule $(1,50,0)$ indicates moving average of short term is one day, moving average of long term is 50 days, and not using price filter(or filter equal zero).

\subsubsection{Simple Moving Averages Rules Improved by Price Filter}

To improve performance of simple moving averages, by reducing wrong signals through adding price filter of 
used moving average, that buying and sale signs will be produced from, while filter is certain percentage of moving average of short term that is added to it before producing sale signal, Filtering percentage of $1 \%$ will be used with every average of short term two moving averages that are used in the study (Day average, average of 5 days). A small percentage were used, because using big ones will avoid signals that increase profit, Three new rules of trading are formed which are $(1,50,1),(1,150,1),(5,150,1)$, first rule $(1,50,1)$ indicates that short term moving average is one day, Long term moving average is 50 days, filter percentage $1 \%$.

Signals of buy and sale are produced as per the following:

- Buying signal on average of one day $-1 \%$ of one day average value > average 50 days.

- Selling signal on average of one day $+1 \%$ of one day average value $<$ Average 50 days.

Table 1. Number of buying and selling signals of technical analysis rules

\begin{tabular}{ccccc}
\hline Technical Analysis rules & No. of buying Signals & \% & No. of selling Signals & \% \\
\hline (1, 50, 0) First Period & 23204 & 54 & 19640 & 46 \\
Second Period & 14532 & 43 & 19116 & 57 \\
Total of the period & 37736 & 49 & 38756 & 51 \\
$(1,50,1)$ first period & 20498 & 52 & 19024 & 48 \\
Second Period & 13008 & 41 & 18660 & 59 \\
Total of Period & 33506 & 47 & 37684 & 53 \\
$(1,150,0)$ first period & 19752 & 46 & 23096 & 54 \\
Second Period & 11010 & 33 & 22646 & 67 \\
Total of Period & 30762 & 40 & 45742 & 60 \\
$(1,150,1)$ first period & 18980 & 46 & 22154 & 54 \\
Second Period & 11548 & 35 & 21110 & 55 \\
Total of Period & 30528 & 41 & 43264 & 59 \\
(5, 150, ) first period & 17077 & 41 & 24383 & 59 \\
Second Period & 11426 & 35 & 21154 & 65 \\
Total of Period & 28503 & 38 & 45537 & 62 \\
(5, 150, 1) first period & 19780 & 46 & 23070 & 54 \\
Second Period & 11379 & 33 & 22760 & 67 \\
Total of Period & 31159 & 40 & 45830 & 60 \\
\hline
\end{tabular}

Table 1 presents the number of buying and selling as following after applying previous technical analysis rules. Based on the table figures, one can notice that the total of selling signals is more than buying signals for all technical analysis rules, since number of selling signals is from $46 \%$ to $67 \%$ from total signals, but buying signals is from $33 \%$ to $54 \%$ of total signals, this means that Egyptian market is Bear Market during period of the study.This indicated the Egyptian stock market during the period of the study was in a condition in which securities prices fell and widespread pessimism caused the stock market's downward spiral to be self-sustaining. When the study period was divided into two sub periods: First period (Pre revolution)and Second period (After revolution), the researcher found that the second period was responsible of raising selling signals than buying signals ,since selling signals were ranged from 55\% to $67 \%$ of total signals. However, by using price filter of simple moving averages rules reduced the selling and buying signals with rate of $3 \%$ to $7 \%$ of total signals, which reduced the transaction cost.

\section{The Analysis of the Study}

The research analysis is a systematic approach to investigations during which numerical data is collected and/or the researcher transforms what is collected or observed into numerical data. It often describes a situation or event; answering the 'what' and 'how many' questions you may have about something. The quantitative approach employed by this study is often concerned with finding evidence to either support or contradict the research hypothesises proposed by the study. The rest of this section is organised based on the research hypothesises proposed by the study.

\subsection{Testing the First Hypothesis}

This sub-section is composed of two main steps to define Significant Differences between return of technical analysis strategies and return of hold and buy strategies: 
First Step: using $T$ test to examine significant differences between short term moving average and long term moving average, since both of them determine decision of buying and selling rules of technical analysis. However, if short term average more than long term average, then buying signal is generated, If short term moving average smaller than long term moving average then selling signal is generated, results of $T$ Test are included in Table 2. As per table number (2), the following is concluded:

There is a significant relationship between average of one day and average of 50 days $<5 \%$, which indicates possibility of using two technical analysis rules $(1,50,0),(1,50,1)$, through the comparison between the one day average and the 50 days average. In addition to that, there is a significant differences between average of one day and average of 150 days, significant level $<1 \%$, which indicates the possibility of using the two technical analysis rules $(1,150,0),(1,150,1)$, through comparing average of one day and 150 days. Finally, a significant differences relationship found between average of five days and average of 150 days, significant level < $1 \%$, which indicates possibility of using two technical analysis rules $(5,150,0),(5,150,1)$, throughout comparing average of five days and 150 days.

Table 2. Results of $\mathrm{T}$ test to estimate significant differences between short term moving average and long term moving average

\begin{tabular}{ccccc}
\hline Short-term moving average & Long-term moving average & T test & P Value & Decision \\
\hline One day & 50 Days & 2.42 & $* 0.014$ & Significant \\
One Day & 150 days & -3.698 & $* * 0.001$ & Significant \\
5 days & 150 days & -4.062 & $* 0.000$ & Significant \\
\hline
\end{tabular}

Note. * Significant level less than 5\%; ** Significant level less than $1 \%$.

Second Step: Test of Significant differences between return of Buy and Hold strategy and returns of Technical analysis rules:

$T$ test is applied to examine significant differences between foresaid Technical rules and hold and buy strategy, which is defined by average of daily return of 46 shares during period of the study, and can be described by following statistics:

Based on Tables 3 and 4 one can conclude that:

However, it should be mentioned that the annual return is calculated through the following equation: $=$ [(Daily return +1$)^{238}-1$ ]. Given that annual trading day per days equal to 238 (CFA program curriculum, 2015). There is a significant relationship between the first rule and Hold and Buy strategy at less significant level, less than $1 \%$, this differences gives an advantage to the technical analysis rule as daily return for this rule is 0.0059 (305\% annually), however, the Daily return of hold and buy strategy is 0.00094 (25\% annually). Moreover, there are significant differences between second strategy and hold and buy strategy at low significant level less than $1 \%$, these differences support the Technical analysis rule since daily return of this rule 0.0059 (305\% annually), although daily income for buy and hold strategy is 0.00094 (25\% annually).

There are significant strategies between third rule and hold and buy strategy at significant level less than $1 \%$, these differences once again alongside with the technical analysis rule, whereas daily income for this rule is 0.00336 ( $122 \%$ annually), whereas daily return for buy and hold strategy is 0.00094 ( $25 \%$ annually). Besides, there are significant differences between forth strategy and hold and buy strategy at level less than $1 \%$, these results once more in conjunction with technical analysis rule as daily income of this rule is 0.00136 (38\% annually), while daily income of hold and buy strategy is 0.00094 ( $25 \%$ annually).

Table 3. Descriptive statistics for the study sample (Hold and Buy strategy)

\begin{tabular}{ccc}
\hline Volume of the sample & Arithmetic mean & Standard deviation \\
\hline 76506 & 0.00094 & 0.0574 \\
\hline
\end{tabular}


Table 4. Results of $\mathrm{T}$ test of significant differences between return of Buy and Hold strategy and Technical analysis rules return

\begin{tabular}{|c|c|c|c|c|c|}
\hline \multicolumn{3}{|c|}{ Technical Analysis Rules } & \multirow{2}{*}{ T test } & \multirow{2}{*}{ P Value } & \multirow{2}{*}{ Decision } \\
\hline Rules & Moving Average & Standard deviation & & & \\
\hline$(1,50,0)$ & 0.0059 & 0.0382 & -19.058 & $* * 0.001$ & Significant \\
\hline$(1,50,1)$ & 0.0059 & 0.0179 & -20.866 & $* * 0.005$ & Significant \\
\hline$(1,150,0)$ & 0.00336 & 0.0387 & -7.188 & $* * 0.000$ & Significant \\
\hline$(1,150,1)$ & 0.00136 & 0.0182 & -9.335 & $* * 0.003$ & Significant \\
\hline$(5,150,0)$ & 0.000636 & 0.0388 & -0.387 & 0.751 & Not Significant \\
\hline$(5,150,1)$ & 0.000427 & 0.0182 & -0.350 & 0.901 & Not Significant \\
\hline
\end{tabular}

** Significant level less than $1 \%$.

However, There are not significant differences between the fifth strategy and hold and buy strategy, because this rule does not make high return, as its daily return was 0.000636 (16.34\% annually). Besides, There is not a significant relationship between sixth strategy and hold and buy strategy, since this rule does not create great return, hence its daily return was 0.000427 (10.7\% annually).

In short, $67 \%$ of technical analysis rules, which are used with short term moving average for one day $(1,50,0)$, $(1,50,1),(0,150,1),(1,150,1)$, could achieve abnormal returns more than return of Hold and Buy strategy ranged between $38 \%$ to $213 \%$ annually, against $25 \%$ only achieved by the Hold and Buy strategy which proved its ability to cover transaction cost and to outperform the traditional Hold and buy strategy.

\subsection{Testing the Second Hypothesis}

To define significant differences between the first period (before revolution) and second period (after revolution), this Hypothesis testing will go through two stages:

First: Testing the significant differences between Buy and Hold strategy return of first period against the second period, by using T Test:

Table 5. Results of $\mathrm{T}$ test to measure significant differences between buy and hold strategy of first period compared to the second period

\begin{tabular}{lccccc}
\hline Statistics & First period & Second period & T test & P Value & Decision \\
\hline Sample volume & 25365 & 51141 & & & \\
Arithmetic mean & 0.000945 & 0.000161 & 2.621 & $* 0.010$ & Significant \\
Standard deviation & 0.03404 & 0.08700 & & & \\
\hline
\end{tabular}

* Significant level less than $5 \%$.

Based on Table 5 there is a significant differences less than $5 \%$, which are related to the first period, as daily return of this period 0.000945 ( $25.20 \%$ annually), higher than daily return of second period which is 0.000161 (3.90\% annually), as second period (after 25th revolution) is period of prices and returns reduction due to unstable events in the market. For example, in 2011, foreign investors' deals sales size of 4.35 billion pounds exceeded purchases size of 194 billion pounds that rendered negative net dealing.

Second: Test of significant differences between returns of Technical analysis rules of first period against the second by using T TEST.

According to Table 6, the following is concluded:

There is no significant difference found between first and second period in first rule $(1,50$, and 0$)$. As the daily return of first rule during first period 0.00456 (195\% annually), while the daily return during second period 0.00505 ( $231 \%$ annually).Besides, there is no significant differences between first and second period in the second rule $(1,50,1)$, by means of the daily return of second rule during first period 0.00467 (203\% annually) compared to the daily return during second period 0.00500 (227\% annually). 
Table 6. Results of $\mathrm{T}$ test to measure significant differences between technical analysis rules returns of first period compared to second period

\begin{tabular}{|c|c|c|c|c|c|c|c|}
\hline \multicolumn{5}{|c|}{ Technical Analysis Rules } & \multirow{3}{*}{ T Test } & \multirow{3}{*}{$P$ value } & \multirow{3}{*}{ Decision } \\
\hline \multirow{2}{*}{ Used rules } & \multicolumn{2}{|c|}{ Arithmetic mean } & \multicolumn{2}{|c|}{ Standard Deviation } & & & \\
\hline & First period & Second period & First Period & Second Period & & & \\
\hline$(1,50,0)$ & 0.00456 & 0.00505 & 0.0285 & 0.0279 & -1.269 & 0.404 & Not Significant \\
\hline$(1,50,1)$ & 0.00467 & 0.00500 & 0.0280 & 0.0280 & -2.533 & 0.172 & Not Significant \\
\hline$(1,150,0)$ & 0.00197 & 0.00300 & 0.0290 & 0.0290 & -3.556 & $* * 0.001$ & Significant \\
\hline$(1,150,1)$ & 0.00195 & 0.00301 & 0.0287 & 0.0279 & -3.699 & $* * 0.003$ & Significant \\
\hline$(5,150,0)$ & 0.00028 & 0.00096 & 0.0290 & 0.0290 & -3.271 & $* 0.019$ & Significant \\
\hline$(5,150,1)$ & 0.00028 & 0.00093 & 0.0290 & 0.0279 & -3.226 & $* 0.018$ & Significant \\
\hline
\end{tabular}

* Significant level less than 5\%; ** Significant level less than $1 \%$.

However, there are significant differences between first and second period in third rule $(1,150,0)$ at significant level less than $1 \%$. Given that the daily return in the first period 0.00197 (59.74\% annually), while in the second period 0.00300 (103\% annually).In addition, significant differences are available between first and second period related to fourth rule $(1,150,1)$ at significant level less than $1 \%$. Whereas daily return of second period is 0.00301 (104\% annually) while daily return of first period is 0.00195 (58.98\% annually).

Furthermore, there is significant relationship between first and second period related to fifth rule $(5,150,0)$ at significant level less than 5\%. While daily return of the first period 0.00028 (6.89\% annually), the daily return of second period is $0.00096(25.65 \%$ annually). Finally, there are significant differences between first and second period related to sixth rule $(5,150,1)$ at significant level less than $5 \%$. The daily return of the first period is 0.00028 (6.89\%), and for the second period is 0.00093 (24.76\% annually).

To sum up, significant differences of Buy and Hold strategy are related to first period, while significant differences of technical analysis rules are related to second period, which means that Technical analysis achieved abnormal returns in inefficiency periods. There are significant differences between first and second period for both fifth and sixth rule, although there are not differences between fifth rule and hold and buy strategy, and between sixth rule and Buy and Hold strategy (Results of first Hypothesis), which means that it can be used to make profits more than Buy and hold strategy in second period (periods of inefficiency).

\section{Conclusion}

ECM show distinctive features that support investors perform diversification within their portfolio. Standard statistical tests may not entirely reveal the possibility for abnormal return to be attained in developing markets because of some distinctive characteristics. Theoretically, the lack of the comprehensive and appropriate institutional setups that support financial markets in most emerging markets recommends that prices will be more predictable. The choice of emerging markets generally, and the Egyptian stock exchange specifically, is motivated by first the fact that this block of economies is under-researched, but second the institutional environment in which these markets are operating attracts inefficiencies. To further develop technical analysis research in emerging markets, there is a need to further explore dynamic trading rules. This study implemented data from one emerging market stock market, Egypt, in order to produce a more comprehensive data set of ECM country and to distinguish from previous studies.

Generally indicatiors of sale are more than indications of buy during period of the study; especially the second period (after revolution) is a descending market. Besides, 67\% of technical analysis rules achieved abnormal returns, more than Buy and hold strategy during research period, indicating its ability to cover transaction cost. Technical analysis rules (Third, fourth, fifth and sixth rule), differences occurred in second period, as return increased in second period, which indicates abnormal profitability of Technical analysis, more than Buy and hold strategy during inefficiency periods (After Revolution).

Thus, the technical analysis rules are effective and have high ability to predict the stock value. This is because of the lack of financial efficiency in the Egyptian stock market, especially in the second period after the revolution, making the application of the simple technical trading rules feasible and profitable. The results of the study are supported by the results of the former studies discussed in the previous studies section, for instance, Wafi, Hassan, and Mabrouk (2015), Assaleh, El-Baz, and Al-Salkhadi (2011), Xavier, Massoud, and Chien (2010).

However, the study recommendations could be summarised in the following points: 
- Using Technical analysis rules which depend on Moving Average improved by filter as they reduces indications of buy and sale and transaction costs.

- Using Technical analysis rules especially in periods of inefficiency markets, where abnormal revenues could be gained.

- Using Moving averages rules which depend on average of one day as short term average, because they achieved the highest returns.

- Training individual investor on technical analysis rules that increase investment consciousness and importance of taking investment decision based on proficient data and information analysis.

For future studies, this study concludes that research in technical analysis methods is still ongoing, although it has been approved only on the basis of past data. On the other hand, the latest studies using complex models (e.g. neural network analysis, genetic algorithm and genetic programming) have made technical analysis more effective in developed and emerging markets. As a result, markets that are no longer effective represent an obstacle to the success of the technical analysis. Accordingly ,the researcher recommends one of the advanced methods and their application in developed and emerging markets to discover whether a specific theoretical framework model of the study can be generalised or not, as well as, to compare the degree of their success.

In conclusion, this study proposes a view that a new orientation does not revoke the significance of the theory of efficiency proposed by Fama (1970, 1991, and 1995); instead, it draws researchers' attention to complementary studies that are more advanced than those of other traditional technical analysis models. The researcher is calling for a combination of studies on financial and operational research models to obtain more accurate results. While all sciences are closely interrelated and must not be separated, therefore, this study could be considered as a new departure for further studies in this area.

\section{References}

Atmeh, A. M., \& Dobbs, M. I. (2006). Technical analysis and the stochastic properties of the Jordanian stock market index return. Studies in Economics and Finance, 23, 119-140. http://dx.doi.org/10.1108/10867370610683914

Bagheri, A., Peyhani, H. M., \& Akbari, M. (2014). Financial forecasting using ANFIS networks with quantum-behaved particle swarm optimisation. Expert Systems with Applications, 41, 6235-6250. http://dx.doi.org/10.1016/j.eswa.2014.04.003

Bekaert, G., \& Harvey, C. R. (2003). Emerging markets finance. Journal of Empirical Finance, 10, 3-55.

Bessembinder, H., \& Kalok, C. (1995). The Profitability of Technical Trading Rules in the Asian Stock Markets. Pacific-Basin Finance Journal, 3, 257-84. http://dx.doi.org/10.1016/0927-538X(95)00002-3

Brock, W., Josef, L., \& Blake, L. (1992). Simple Technical Trading Rules and the Stochastic Properties of Stock Returns. Journal of Finance, 47, 1731-764.

Charles, D., Kirkpatric, J., \& Dahlquistk, A. (2016). Technical Analysis: The Complete Resource for Financial Market Technicians (3nd ed.). Pearson Education.

Cheol-HO, P., \& Scott, H. I. (2007) .What Do You Know about the Profitability of Technical Analysis. Journal of Economic Surveys, 21, 786-826. http://dx.doi.org/10.1111/j.1467-6419.2007.00519.x

Curcio, R., Charles, G., Dominique, G., \& Richard, P. (1997). Do Technical Trading Rules Generate Profits? Conclusions from the Intra-Day Foreign Exchange Market. International Journal of Finance and Economics, 2, 267-280. http://dx.doi.org/10.1002/(SICI)

Daniel, K., Hirshleifer, D., \& Subrahmanyam, A. (1998). Investor Psychology and security market under and over reaction. The Journal of Finance, 1839-1885.

Day, T. E., \& Wang, P. (2002). Dividends, Nonsynchronous Prices, and the Returns from Trading the Dow Jones Industrial Average. Journal of Empirical Finance, 9, 431-454. http://dx.doi.org/10.1016/S0927-5398(02)00004-X

De Oliveira, F. A., Nobre, C. N., \& Zrate, L. E. (2013). Applying artificial neural networks to prediction of stock price and improvement of the directional prediction index - Case study of PETR4, Petrobras, Brazil. Expert Systems with Applications, 40, 7596-7606. http://dx.doi.org/10.1016/j.eswa.2013.06.071

Dewachter, H., \& Marco, L. (2005). The Economic Value of Technical Trading Rules: A Nonparametric Utility-Based Approach. International Journal of Finance and Economics, 10, 41-62. 
Fama, E. F. (1970). Efficient Capital Markets: A Review of Theory and Empirical Work. Journal of Finance, 25, 383-417.

Fayek, M. B., Boghdadi, H. M., \& Omran, S. M. (2013). Multi-objective optimization of technical stock market indicators using gas. International Journal of Computer Applications, 68, 41-48.

Froot, K. A., Scharfstein, D. S., \& Stein, J. C. (1992). Herd on the Street: Informational Inefficiencies in a Market with Short-Term Speculation. Journal of Finance, 47, 1461-1484.

Gehrig, T., \& Lukas, M. (2006). Extended Evidence on the Use of Technical Analysis in Foreign Exchange. International Journal of Finance and Economics, 11, 327-338. http://dx.doi.org/10.1002/ijfe.301

Gençay, R. (1998). The Predictability of Security Returns with Simple Technical Trading Rules. Journal of Empirical Finance, 5, 347-359.

Gottschlich, J., \& Hinz, O. (2014). A decision support system for stock investment recommendations using collective wisdom. Decision Support Systems, 59, 52-62. http://dx.doi.org/10.1016/j.dss.2013.10.005

Gunasekarage, A., \& Power, D. M. (2001). The profitability of moving average trading rules in South Asian stock markets. Emerging Markets Review, 2, 17-33.

Hong, H., \& Jeremy, C. S. (1999). A unified theory of under-reaction, momentum trading and overreaction in asset markets. Journal of Finance, 54, 2143-2184.

Hu, Feng, B., Zhang, X., Ngai, E., \& Liu, M. (2015). Stock trading rule discovery with an evolutionary trend following model. Expert Systems with Applications, 42, 222. http://dx.doi.org/10.1016/j.eswa.2014.07.059

Jennings, G. (2001). Tourism Research (3rd ed.). Milton: John Wiley \& Sons.

Kung, J. J., \& Wong, K. W. (2009). Profitability of technical analysis in the Singapore stock market: Before and after the Asian financial crisis. Journal of Economic Integration, 24, 135-150.

Kwon, K. Y., \& Kish, R. (2002). A Comparative Study of Technical Trading Strategies and Return Predictability: Using NYSE and NASDAQ Indices. Quarterly Review of Economics and Finance, 42, 611-631. http://dx.doi.org/10.1016/S1062-9769(01)00089-8

Lo, A., Mamaysky, H., \& Wang, J. (2000). Foundations of Technical Analysis: Computational Algorithms, Statistical Inference, and Empirical Implementation. Journal of Finance, 55, 1705-1765.

Lukac, L. P., \& Brorsen, B. W. (1989).The Usefulness of Historical Data in Selecting Parameters for Technical Trading Systems. Journal of Futures Markets, 9, 55-65. http://dx.doi.org/10.1002/fut.3990090106

Malliaris, T., \& Malliaris, M. (2013). N-Tuple S\&P 500 index patterns across decades, 1950s to 2011. Working paper. http://dx.doi.org/10.2139/ssrn.2348357

Mallick, D., Lee, V. C., \& Ong, Y. S. (2008). An empirical study of genetic programming generated trading rules in computerised stock trading service system. Retrieved from http://citeseerx.ist.psu.edu/viewdoc/summary?doi=10.1.1.205.5503

Masry, M. (2016a). The Dealers Characteristics and Their Impact on Their Investment Decisions Efficiency in Egyptian Stock Exchange. International Journal of Recent Scientific Research, 7, 8294-8301.

Masry, M. (2016b). The Impact of Institutional Ownership on the Performance of Companies Listed In the Egyptian Stock Market. IOSR Journal of Economics and Finance (IOSR-JEF), 7, 5-15. http://dx.doi.org/10.9790/5933-07130515

Mounir, I. H. (2013). Securities and Capital Mark (6th ed.). Monshaat El Maaref Library.

Murphy, J. J. (1999). Technical Analysis of the Financial Markets: A Comprehensive Guide to Trading Methods and Applications. New York: New York Institute of Finance.

Oberlechner, T. (2001). Importance of Technical and Fundamental Analysis in the European Foreign Exchange Market. International Journal of Finance and Economics, 6, 81-93. http://dx.doi.org/10.1002/ijfe.145

Patel, J., Shah, S., Thakkar, P., \& Kotecha, K. (2015). Predicting stock and stock price index movement using trend deterministic data preparation and machine learning techniques. Expert Systems with Applications, 42, 259-268. http://dx.doi.org/10.1016/j.eswa.2014.07.040

Peterson, I. D. (2006). The Relationship between Technical Analysis Generated Returns and the Fama and Frensh Risk Factors as Applied to Individual Securities (PhD thesis). The Florida State University. 
Ratner, M., \& Leal, R. P. C. (1999). Tests of technical trading strategies in the emerging equity markets of Latin America and Asia. Journal of Banking and Finance, 23, 1887-1905. http://dx.doi.org/10.1016/S0378-4266(99)00042-4

Robert, D. E., \& John, M. (2001). Technical Analysis of Stock Trends (8th ed.). Stock Trend Service

Sager, M. J., \& Mark, P. T. (2006). Under the Microscope: The Structure of the Foreign Exchange Market. International Journal of Finance and Economics, 11, 81-95.

Shiller, R. J. (1990). Speculative Prices and Popular Models. Journal of Economic Perspectives, 4, 55-65.

Silva, A., Neves, R., \& Horta, N. (2015). A hybrid approach to portfolio composition based on fundamental and technical indicators. Expert Systems with Applications, 42, 2036-2048. http://dx.doi.org/10.1016/j.eswa.2014.09.050

Steven, A. (2001). Technical Analysis from A to Z (2nd ed.). McGraw-Hill.

Tian, G. G., Wan, G. H., \& Guo, M. (2002). Market efficiency and the returns to simple technical trading rules: New evidence from U.S. equity market and Chinese equity markets. Asia-Pacific Financial Markets, 9, 241-258.

Vasileiou, E. (2014). Is technical analysis profitable even for an amateur investor? Evidence from the Greek stock market (2002-12). Behavioral Finance and Investment Strategies: Decision Making in the Financial Industry, 10, 255-269. http://dx.doi.org/10.4018/978-1-4666-7484-4.ch015

Wafi, A. S., Hassan, H., \& Mabrouk, A. (2015). Fundamental analysis vs. technical analysis in the Egyptian stock exchange-Empirical study. International Journal of Business and Management Study-IJBMS, 2, 212-218. http://dx.doi.org/10.1016/S2212-5671(15)01344-1

Welman, J. C., \& Kruger, S. J. (2001). Research Methodology (2nd ed.). Cape Town: Oxford University Press.

West, K. D. (1996). Asymptotic inference about predictive ability. Econometrica, 64, 1067-1084.

Yin-Wong, C., Menzie, D. C., \& Ian, W. M. (2004). How Do UK-based Foreign Exchange Dealers Think their Market Operates? International Journal of Finance and Economics, 9, 289-306. http://dx.doi.org/10.3386/w7524

Zbikowski, K. (2015). Using volume weighted support vector machines with walk forward testing and feature selection for the purpose of creating stock trading strategy. Expert Systems with Applications, 42, 1797-1805. http://dx.doi.org/10.1016/j.eswa.2014.10.001

\section{Copyrights}

Copyright for this article is retained by the author(s), with first publication rights granted to the journal.

This is an open-access article distributed under the terms and conditions of the Creative Commons Attribution license (http://creativecommons.org/licenses/by/4.0/). 